\title{
Straight and Branched Sucrose Monoamide Derivatives as New Surfactants
}

\author{
SALIH MAHDI SALMAN \\ Department of Chemistry, Faculty of Medicine, University of Diyala, Iraq \\ waamrs@yahoo.com
}

Received 20 November 2015 / Accepted 11 January 2016

\begin{abstract}
We have synthesized monoamide analogs of sucrose. The synthesis applied a multi steps synthesis scheme ended by Staudinger reaction based coupling of a sucrose azide with fatty acid chlorides. Sucrose monoamide surfactants are easily accessible surfactants from sucrose, which is consider as the cheapest natural carbohydrate resources. The assembly behavior of synthesized monoamide derivatives was investigated by optical polarizing microscopy, Differential scanning calorimetry DSC and surface tension studies. These surfactants exhibit very good solubility in water at room temperature and value of $\mathrm{CMC}$ within the range of disaccharides surfactants, which make those surfactants fitting the target application as water-in-oil emulsions.
\end{abstract}

Keywords: Bioactive surfactants, Monoamide surfactants, Staudinger reaction, Carbohydrate surfactants, Oil -in-water emulsion, Hexagonal phase and sugar based surfactants

\section{Introduction}

Sucrose is a non-reducing disaccharide that occurs naturally in most fruit and vegetable. The structure is shown in Figure 1. It is produced in large quantities, e.g. in sugar cane and sugar beets, from which it is isolated for commercial use. The annual production of sucrose is about 168 million tons. Sucrose is the less expensive carbohydrate on the world market. Sucrose production exceed world market demand by over million tons ${ }^{1}$. Because of that, more application of sucrose is needed ${ }^{2}$. The aim of this series is to synthesize sucrose monoamides by replacement of the hydroxyl group at position 6 of fructose with straight and branched $\mathrm{C}_{12}$ alkyl chains via Staudinger reaction. The target application of sucrose surfactants are water -in oil emulsifier.

Due to the three primaries and five secondary hydroxyl groups (Figure 1), sucrose will be a great candidate for water-in-oil emulsions, which is fitting the target application for those surfactants, but the chemical reactions of unprotected sucrose in a single hydroxyl group is a big challenge. The suitable reactivity differences between primary and secondary hydroxyl groups have been generalized such that the three primary ones alkylated, acylated, oxidized and displaced by halogen in the order $6-\mathrm{OH}$ glucose $=6-\mathrm{OH}$ fructose $>>1-\mathrm{OH}$ fructose, an over generalization as this order of reactivity mainly cover comparatively bulky reagents, which necessarily favor reaction at the 6-OH glucose and 6-OH fructose groups ${ }^{3}$. 


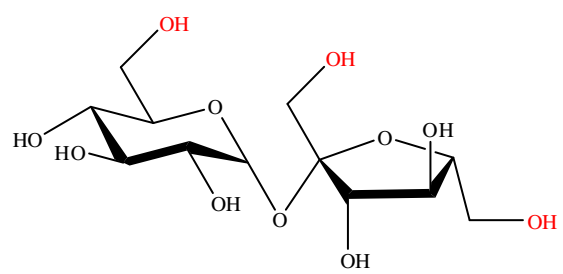

Figure 1. Chemical structure of sucrose

\section{Experimental}

Melting points were determined using a manual melting point apparatus and are uncorrected. Optical rotations were measured at $589 \mathrm{~nm}$ in $10 \mathrm{~cm}$ cells at room temperature. NMR spectra were recorded on Jeol and Bruker spectrometers at $400 \mathrm{MHz}$ for ${ }^{1} \mathrm{H}$ and $100 \mathrm{MHz}$ for ${ }^{13} \mathrm{C}$, respectively. Assignments of ${ }^{13} \mathrm{C}$-signals are based on $\mathrm{HMQC}$ spectra ${ }^{4,5}$. High-resolution mass spectra were recorded on an LC-MS system, applying $\mathrm{MeOH} /$ water eluents. Phase transition temperatures were determined by DSC in replicated heating-cooling cycles at a heating/cooling rate of $10{ }^{\circ} \mathrm{C}$ min. Lyotropic phases were investigated using the contact penetration technique under OPM observation ${ }^{6}$. The determination of Krafft points applied heating $20 \mathrm{~mL}$ samples of the surfactant in water at a concentration of about $10 \%$ above the $\mathrm{CMC}$ in an oil bath under moderate stirring until the mixture cleared. Critical micelle concentrations were determined by surface tension measurements $\mathrm{s}^{7-9}$. The intersection of the concentration dependent and the high concentration independent region in the plot of the surface tension versus the logarithmic concentration determines the CMC. Surface tension measurements were measured at r.t. in 5 replicates with a standard deviation below $0.1 \mathrm{mN} \mathrm{m}$.

\section{General procedures}

\section{Tert-butyldiphenylsilylation}

4-Dimethylaminopyridine ( 0.026 eq.) was added to the mixture of sucrose (1.0 eq.) and tertbutyldiphenylsilyl chloride (1.1 eq.) in pyridine $(25 \mathrm{~mL}$ per one gram). The mixture was stirred at room temperature and monitored by TLC using (ethyl acetate-acetone-water, 10:10:1) as eluent. When the TLC showed consumption of the starting materials, the mixture was concentrated and used for the next reaction without further purification.

\section{Acetylation}

Acetic anhydride ( $2 \mathrm{~mL}$ per one hydroxyl group) was added to sugar derivatives (1.0 eq.) in pyridine. The mixture was stirred at room temperature and monitored by TLC using hexane-ethyl acetate 3:1 as an eluent. When the TLC showed the consumption of the starting materials, the solvent was removed at reduced pressure. The residue was dissolved in dichloromethane and washed with sodium hydrogen carbonate solution and water, dried over magnesium sulfate and concentrated. The compound was used for the next reaction without further purification.

\section{Desilylation}

The solution of tert-butyldiphenylsilyl-sucrose peracetate (1.0 eq.) in tetrahydrofuran ( $25 \mathrm{~mL}$ per one gram) was treated at room temperature with tetra-butylammonium fluoride (1.1eq. $1 \mathrm{M}$ solution in THF). The reaction was monitored by TLC (hexane- ethyl acetate, 3:1), When the starting material was consumed (about 5 hours), the solvent was evaporated and the residue was dissolved in dichloromethane (DCM). The organic solution was washed with water, dried over magnesium sulfate and concentrated. The compound was utilized for the next reaction without further purification. 


\section{Tosylation}

To the solution of sugar derivatives (1.0 eq.) in pyridine ( $25 \mathrm{~mL}$ per gram) was added tosyl chloride (1.0 eq.). After about 24 hours TLC (hexane-ethyl acetate $3: 1$ ) showed consumption of the starting material. The mixture was poured into ice water and extracted with dichloromethane for three times. The combined extracts were evaporated and the residue was subjected to azidation without further purification.

\section{Azidation}

A suspension of sugar tosylate (1.0 eq.) and sodium azide $\mathrm{NaN}_{3}(6.0$ eq) in $\mathrm{N}, \mathrm{N}$ dimethylformamide DMF (20 mL per gram) was heated to $80^{\circ} \mathrm{C}$ for 24 hours. The solution was cooled to room temperature, diluted with water and extracted with dichloromethane. The organic layer was washed with water, saturated $\mathrm{NaHCO}_{3}$ solution and water, dried over $\mathrm{MgSO}_{4}$ and concentrated under reduced pressure. After acetylation with acetic anhydride (2.0 eq.) in pyridine ( $20 \mathrm{~mL}$ per gram) and recrystallization with ethanol NMR pure white azide was obtained in very good yield.

\section{Staudinger reaction}

Fatty acid chloride (1.6 eq.) in $(5 \mathrm{~mL})$ of dichloromethane was added drop wise at room temperature to a mixture of acetylated sugar azide (1 eq.) and triphenylphosphine (1.2 eq.) in $(20 \mathrm{~mL})$ of dichloromethane. Stirring was continued for about 15 hours at room temperatureto obtain cloudy solution. The solid was filtered of and the solution was washed with $5 \%$ solution of sodium hydrogen carbonate, dried over magnesium sulfate and evaporated to dryness. The resulting syrup was chromatographed on silica gel with 6:1 ethyl acetate- acetone as eluent to affordthe protected derivatives as white NMR pure crystals.

\section{Deacetylation}

The peracetylated amide derivatives was dissolved in methanol $(25 \mathrm{~mL}$ per one gram) and treated with a catalytic amount of sodium methoxide to obtain a basic medium. The mixture was stirred for 24 hours at room temperature and monitored by TLC (dichloromethane: ethanol 9:1). The basic catalyst was removed with Amberlite IR $120\left(\mathrm{H}^{+}\right)$, the solid was filtered and methanol was evaporated to furnish the surfactant in approximately quantitative yield.

\section{Synthesis of 1',3',4'-hepta-O-acetyl-6'-O-dodecanamido-sucrose (7a)}

Compound 6 (1.5 g, $2.27 \mathrm{mmol}$ ) was coupled with dodecanoyl chloride $\mathrm{C}_{11} \mathrm{H}_{23} \mathrm{COCl}$ and triphenylphosphine $\mathrm{PPh}_{3}$ according to the Staudinger reaction to produce compound 7a $(1.25$ $\mathrm{g}, 68 \%)$ as NMR pure white crystals. $[\alpha]_{\mathrm{D}}{ }^{25}=+33.0\left(\mathrm{c} 0.15, \mathrm{CHCl}_{3}\right){ }^{1} \mathrm{H}$ NMR $(400 \mathrm{MHz}$, $\left.\mathrm{CDCl}_{3}\right) \delta=5.62(\mathrm{~d}, 1 \mathrm{H}, \mathrm{H}-1), 5.42$ (dd t, $\left.1 \mathrm{H}, \mathrm{H}-3\right), 5.39$ (dd t, 1H, H-3'), 5.19 (dd t, 1H, H-4), 5.02 (dd t, 1H, 4'-H), 4.82 (dd, 1H, 2-H), 4.05 - 4.44 (m, 6H, H-1'A, H-1'B, H-5 , H5', H-6B, H-6' A), 3.70 (ddd, 1H, H-6A), 3.32 ( ddd, 1H, H-6'B), 2.17 ( m. 2H, $\alpha-\mathrm{CH}_{2}$ ), 2.14 , 2.09, 2.08, 2.07, 2.06, 2.02, $1.99(7 \mathrm{~s}, 21 \mathrm{H}, \mathrm{Ac}), 1.61\left(\mathrm{~m}, 2 \mathrm{H}, \beta-\mathrm{CH}_{2}\right), 1.22(\mathrm{~s}, 16 \mathrm{H}$, bulk$\mathrm{CH}_{2}$ ), $0.85\left(\mathrm{t}, 3 \mathrm{H}, \mathrm{CH}_{3}\right) .{ }^{3} \mathrm{~J}_{1,2}=3.5,{ }^{3} \mathbf{J}_{2,3}=10.0,{ }^{3} \mathbf{J}_{3^{3}, 4}=9.5,{ }^{2} \mathrm{~J}_{6}=14,{ }^{2} \mathrm{~J}_{6},=13.0,{ }^{3} \mathrm{~J}_{6}, \mathrm{NH}=5.5$. $\mathrm{Hz} \cdot{ }^{13} \mathrm{C}$ NMR $\left(100 \mathrm{MHz}, \mathrm{CDCl}_{3}\right) \delta=173.54(\mathrm{CONH}), 170,66 \times 2,170.11 \times 2,196.98,196.63$, 196,56 ((C=O), 103.86 (C-2'), 89.80 (C-1), 79.90 ( C-5'), 75.85 ( C-3'), 75.83 (C-4'), 70.41 (C-2), 69.37 (C-3), 68.67 (C-5), 68.29 (C-4), 63.40 (C-6), 61.76 (C-1'), 41.37 (C-6'), $36.50\left(\alpha-\mathrm{CH}_{2}\right), 31.88(\omega-2), 29.61,29.59,29.48,29.36,29.31 \times 2\left(\right.$ bulk $\left.-\mathrm{CH}_{2}\right), 25.54\left(\beta-\mathrm{CH}_{2}\right)$, $22.66(\omega-1), 20,75,20.73,20.66 \times 2,20.63,20.60,20.57($ Ac) $), 14.09(\omega)$. Elemental analysis for $\mathrm{C}_{38} \mathrm{H}_{59} \mathrm{NO}_{18}$ : C55.81, H 7.27, N 1.71; found C 55.84, H 7.33, N 1.75. 


\section{Synthesis of 6'-dodecanamido-sucrose (7b)}

Compound 7a $(1 \mathrm{~g})$ was deacetylated with sodium methoxide in methanol according to Zemlplen reaction to give $7 \mathbf{b}(0.6 \mathrm{~g}, 94 \%)$ as NMR pure white crystals.mp $204{ }^{\circ} \mathrm{C}$ (dec.). $[\alpha]_{\mathrm{D}}{ }^{25}=+43.0\left(\mathrm{c} 0.15, \mathrm{CH}_{3} \mathrm{OH}\right){ }^{1} \mathrm{H}$ NMR $\left(400 \mathrm{MHz}, \mathrm{CD}_{3} \mathrm{OD}\right) \delta=3.5(\mathrm{~d} 1 \mathrm{H}, \mathrm{H}-1$, 4.07 ( d, C-5'), 3.89- 3.59 (m, 7H, H-2', H-3', H-3, H-6, H-4, 2H-6'), 2.42 (dd t, 1H, H-2), 3.48 (dd t, 1H, H-1'A), 3.28 (m, 1H, H-1'B), 2.21 ( m, 2H, $\left.\alpha-\mathrm{CH}_{2}\right), 1.61\left(\mathrm{~m}, 2 \mathrm{H}, \beta-\mathrm{CH}_{2}\right)$, 1.31 (s, $16 \mathrm{H}$, bulk- $\left.\left.\mathrm{CH}_{2}\right), 0.91\left(\mathrm{t}, 3 \mathrm{H}, \mathrm{CH}_{3}\right) \mathrm{Hz},{ }^{3} \mathrm{~J}_{1,3}=3.5,{ }^{3} \mathrm{~J}_{2,3}=10.0,{ }^{2} \mathrm{~J}_{6}=13.5\right)$.

${ }^{1} \mathrm{H}$ NMR (400 MHz, CD $\mathrm{CD}_{3} \mathrm{OD} \delta 175.58(\mathrm{CONH}), 104.67$ ( C-2'), 92.16 (C-1), 80.19 (C-3'), 78.10 (C-5', 77.00 (C-5), 73.37 (C-3), 73.08 (C-4'), 72.08 (C-2), 70.64 (C4), 63.23 (C-6), 61.42 (C-1'), $42.29\left(\mathrm{C}-6\right.$ ') ,35.75 $\left(\alpha-\mathrm{CH}_{2}\right), 31.73(\omega-2), 29.40 \times 3,29.12 \times 2,28.99$ x3, 28.94 x2 (bulk- $\left.\mathrm{CH}_{2}\right), 25.64\left(\beta-\mathrm{CH}_{2}\right), 22.38(\omega-1), 13.08(\omega)$. HRMS: $[\mathrm{M}+\mathrm{H}]^{+}$: calcd for $\mathrm{C}_{24} \mathrm{H}_{45} \mathrm{NO}_{11}: 524.3065$ (100\%), 525.3098 (28\%); found : 524.3039 (100\%), 525.3064 (25 $\%$; $[\mathrm{M}+\mathrm{Na}]^{+}$: calcd for $\mathrm{C}_{24} \mathrm{H}_{45} \mathrm{NO}_{11} \mathrm{Na}: 546.2884$ (100\%), 547.2917 (28\%; found: 546.2878 (100\%), 547.2905 (28\%).

\section{Synthesis of 2,3,4,6,1',3',4'-hepta-O-acetyl-6'-O-(2-butyl-octanamido)-sucrose (8a)}

Compound 6 (1.g, $2.27 \mathrm{mmol})$ was coupled with 2-butyloctanoyl chloride $\mathrm{C}_{6} \mathrm{H}_{13}(\mathrm{COCl})$ $\mathrm{C}_{4} \mathrm{H}_{9}$ and triphenylphosphine $\mathrm{PPh}_{3}$ according to the Staudinger reaction to furnish compound 8a $(1 . \mathrm{g}, 65 \%)$ as NMR pure white crystals. $[\alpha]_{\mathrm{D}}{ }^{25}=+27.0\left(\mathrm{c} 0.15, \mathrm{CHCl}_{3}\right) .{ }^{1} \mathrm{H}$ NMR $(400$ $\left.\mathrm{MHz}, \mathrm{CD}_{3} \mathrm{OD}\right) \delta=5.17(\mathrm{~d}, 1 \mathrm{H}, \mathrm{H}-1), 5.48$ ( dd t, 1H, H-3), 5.46 (dd t, 1H, H-3'), 5.06 (dd t, 1H, H-4, 5.32 (dd t, 1H, 4'-H), 4.94 ( dd, 1H, 2-H), 4.23-4.14 (m, 4H, H-1'B, H-5 , H-5', H-6B, H-6' A), 3.71 (ddd, 1H, H-6A), 2.22 (m. 2H, $\left.\alpha-\mathrm{CH}_{2}\right), 3.32$ ( 1H,-CH), 2.19, 2.12, $2.11,2.09,2.08,2.06 .202(7 \mathrm{~s} .21 \mathrm{H}, \mathrm{Ac}), 1.58\left(\mathrm{~m}, 2 \mathrm{H}, \beta-\mathrm{CH}_{2}\right), 1.29(\mathrm{~m}, 16 \mathrm{H}$, bulk$\left.\mathrm{CH}_{2}\right), 0.91\left(\mathrm{t}, 3 \mathrm{H}, \mathrm{CH}_{3}\right) .{ }^{3} \mathrm{~J}_{1,2}=3.5,{ }^{3} \mathrm{~J}_{2,3}=10.0,{ }^{3} \mathrm{~J}_{3}, 4,=9.5,{ }^{2} \mathrm{~J}_{6}=1, \mathrm{~Hz} \cdot{ }^{13} \mathrm{C}$ NMR $(100 \mathrm{MHz}$, $\left.\mathrm{CD}_{3} \mathrm{OD}\right) \delta=177.39(\mathrm{CONH}), 170, .41,170.34 \times 2,170.30,196.92,196,90(\mathrm{C}=\mathrm{O}), 88.96(\mathrm{C}-$ 2'), 79.92 (C-1), 76.27( C-5'), 76.07 ( C-3'), 70.25 ( C-4'), 69.58 ( C-2), 68.69 (C-3), 68.48 (C-5), 68.29 (C-4), 62.95 (C-6), 62.07 (C-1'), 41.71 (C-6), 32.84. $32.74\left(\alpha-\mathrm{CH}_{2} 29.61,29.59\right.$, 32.50, 32.37, 31,98 (bulk- $\left.\mathrm{CH}_{2}\right), 31.4,31.31\left(\beta-\mathrm{CH}_{2}\right), 22.66(\omega-1), 29.47,29.00,28.95$ (Ac), 19.30, $19.15(\omega)$. Elemental analysis for $\mathrm{C}_{38} \mathrm{H}_{59} \mathrm{NO}_{18}$ : C55.81, H 7.27, N 1.71; found $\mathrm{C}$ 55.85, H 7.38, N 1.74 .

\section{Synthesis of 6'-(2-Butyl-octanamido)-sucrose ( $8 \boldsymbol{b})$}

Compound 8a ( $1 \mathrm{~g})$ was deacetylated with sodium methoxide in methanol according to the Zemlplen reaction to give compound $\mathbf{8 b}(0.59 \mathrm{~g}, 92 \%)$ as NMR pure white crystals. $[\alpha]_{\mathrm{D}}{ }^{25}=+43.0\left(\mathrm{c} 0.15, \mathrm{CH}_{3} \mathrm{OH}\right) .{ }^{1} \mathrm{H}$ NMR $\left(400 \mathrm{MHz}, \mathrm{CD}_{3} \mathrm{OD}\right) \delta=5.38(\mathrm{~d}, 1 \mathrm{H}, \mathrm{H}-1), 4.07$ (d, C-5'), 3.89- 3.49 (m, 7H, H-2', H-3',H-3, H-6, H-4, 2H-6'), 3.44( m, 1H, H-2), 3.29 (m, 2H, H-1'A, 1'B), $2.20\left(\mathrm{~m}, 2 \mathrm{H}, \alpha-\mathrm{CH}_{2}\right), 1.56\left(\mathrm{~m}, 2 \mathrm{H}, \beta-\mathrm{CH}_{2}\right), 1.35$ (s, $16 \mathrm{H}$, bulk- $\left.\mathrm{CH}_{2}\right), 0.91$ $\left.\left(\mathrm{t}, 3 \mathrm{H}, \mathrm{CH}_{3}\right) \mathrm{Hz},{ }^{3} \mathrm{~J}_{1,3}=3.5,{ }^{3} \mathrm{~J}_{2,3}=10.0,{ }^{2} \mathrm{~J}_{6}=13.5\right)$.

${ }^{1} \mathrm{H}$ NMR (400 MHz, $\left.\mathrm{CD}_{3} \mathrm{OD}\right) \delta=177.88(\mathrm{CONH}), 104.11(\mathrm{C}-2$ ') $, 92.08(\mathrm{C}-1), 80.28$ (C-3'), 78.52 (C-5'), 77.26 (C-5), 73.34 (C-3), 73.16 (C-4'), 71.97(C-2), 70.46 (C4), 62.97 (C-6), 61.50 (C-1'), 42.50 (C-6'), 32.86, 32.76, 32.53, $32.44\left(\alpha-\mathrm{CH}_{2}\right), 31.53 \times 2$ $(\omega-2), 29.49 \times 3,29.42,29.11,29.05\left(\right.$ bulk- $\left.\mathrm{CH}_{2}\right), 27.21,27.14\left(\beta-\mathrm{CH}_{2}\right), 22.39,22.35$, $22.72(\omega-1), 13.01,12.94(\omega)$. HRMS: $[\mathrm{M}+\mathrm{H}]^{+}$: calcd for $\mathrm{C}_{24} \mathrm{H}_{45} \mathrm{NO}_{11}: 524.3065$ $(100 \%), 525.3098(28 \%)$; found : 524.3163 (very weak); [M+Na $]^{+}$: calcd for $\mathrm{C}_{24} \mathrm{H}_{45} \mathrm{NO}_{11} \mathrm{Na}$ : $546.2884(100 \%), 547.2917$ (28\%); found : 546. 2988 (100\%), $547.3017(24 \%)$. 


\section{Results and Discussion}

\section{Synthesis}

The synthetic scheme is pictured in Figure 2. The reaction of sucrose with 1.1 eq. of the bulky reagent tert-butyldiphenylsilyl chloride (TBDPSCl) led to the sole protect of the hydroxyl group at position 6 of the fructose moiety by yield 6'-O-tert-butyldiphenylsilyl sucrose $(2)^{10-12}$. Afterword remaining hydroxyl groups can be easily acylated with acetic anhydride in pyridine to form the fully protected sucrose compounds 1',2,3,3',4,4',6-hepta-O-acetyl-6'-tertbutyldiphenylsilyl-sucrose $(3)^{13}$. The hydroxyl group at position 6 of fructose can be selectively deprotection with tert-butylammonium fluoride (TBAF) in tetrahydrofuran (THF) to obtain the partially protected $1^{\prime}, 2,3,3^{\prime}, 4,4^{\prime}, 6$-hepta- $O$-acetyl-6' - sucrose (4) ${ }^{14}$.

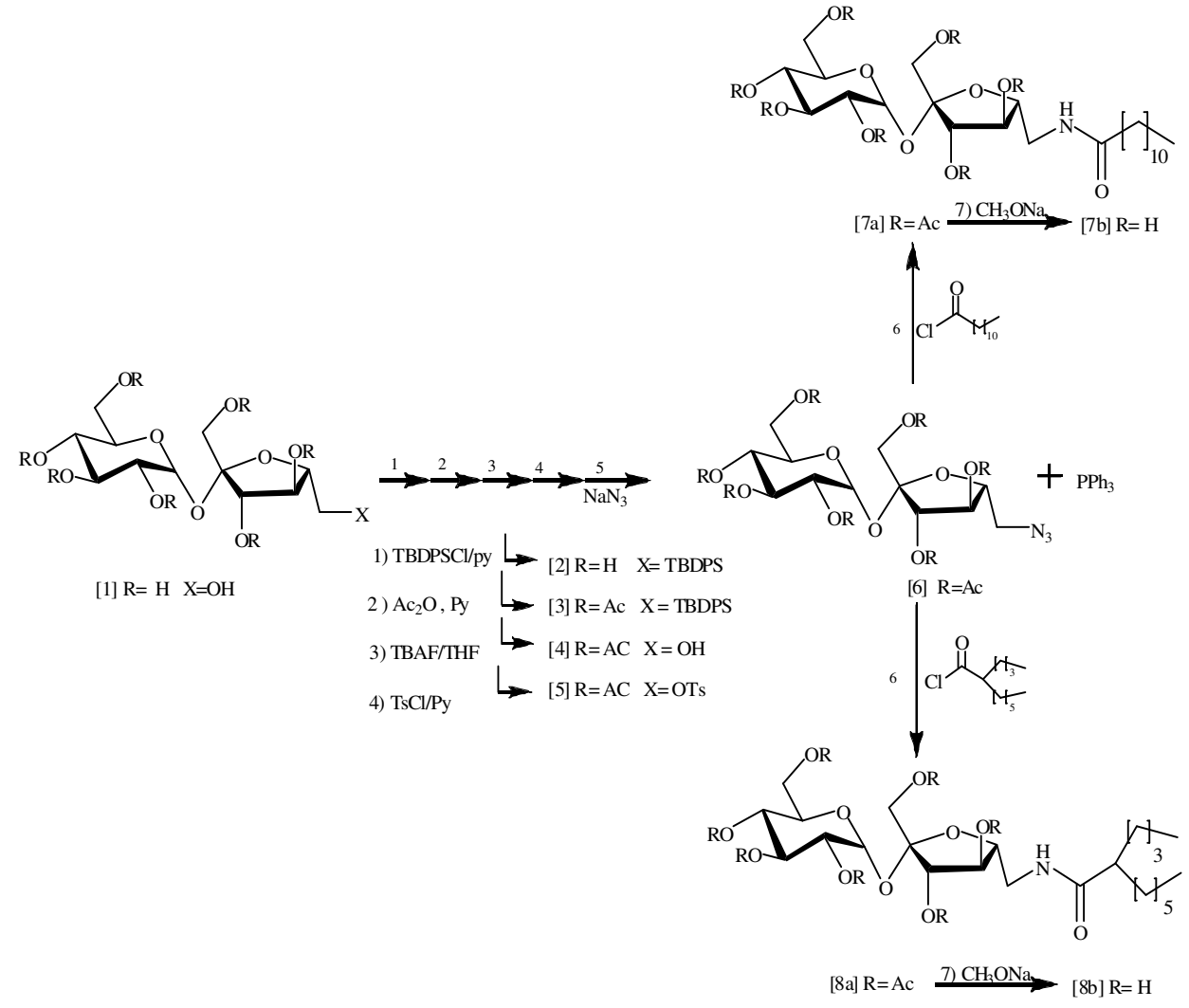

Figure 2. Synthesis of sucrose monoamide surfactants

Activation of 6'-OH applied in pyridine to furnish 1',2,3,3',4,4',6-hepta- $O$-acetyl-6'tosyl-sucrose $(\mathbf{5})^{15}$. The tosyl was substituted with sodium azide in $N, N$-dimethylformamide DMF at $80{ }^{\circ} \mathrm{C}$ to give the surfactant precursor $1^{\prime}, 2,3,3^{\prime}, 4,4^{\prime}, 6$-hepta- $O$-acetyl-6'-azidosucrose $(6)^{16,17}$. Coupling of the latter with dodecanoyl chloride and 2-butyloctanoyl chloride via Staudinger reaction in presence of tryphenylphosphine furnished the actylated surfactants 1',2,3,3',4,4',6-hepta- $O$-acetyl-6'-dodecanamido-sucrose (7a) and 1',2,3,3',4,4',6hepta- $O$-acetyl-6'-2-butyl-octanamido-sucrose (8a) respectively ${ }^{18-20}$. Final deacetylation under Zamplen conditions led to NMR pure surfactants 6'-dodecanamido-sucrose (7b) and 6'-2-butyl-octanamido-sucrose (8b) $)^{21-23}$. 
${ }^{1} \mathrm{H}$ NMR of the acetylated surfactants (Figures 3 and 4) shows the signals of the amide proton at about $\delta 6.00$. The sugar protons appear between $\delta 5.62(\mathrm{H}-1)$ and $\delta 4.40(\mathrm{H}-5)$. The primary proton of fructose found at 3.32 (H-6'B), which indicate the replacement of the oxygen with amide. Acetyl groups are found at about $\delta 2.00$. The alkyl chain protons appear between $\delta 2.2\left(\alpha-\mathrm{CH}_{2}\right)$ and $\delta 0.85$ (terminal- $\left.\mathrm{CH}_{3}\right)$. In ${ }^{13} \mathrm{C}$ NMR (Figures $5 \& 6$ ) the signal for the amide carbon appears at about $\delta 173$, whereas acetyl carbons of the pyranose are found between $\delta 170.5$ and $\delta 170$, while for furanose found between $\delta 197$ and $\delta 196.5$, Sugar carbons appear between $\delta 103$ (C-2') and $\delta 61$ (C-1'). The signal of (C-6') found at $\delta 41$ which indicate the replacement of oxygen with amide. Alkyl chain carbons appear between $\delta 36.5\left(\alpha-\mathrm{CH}_{2}\right)$ and $\delta 14.00\left(\right.$ terminal $\left.\mathrm{CH}_{3}\right)$.

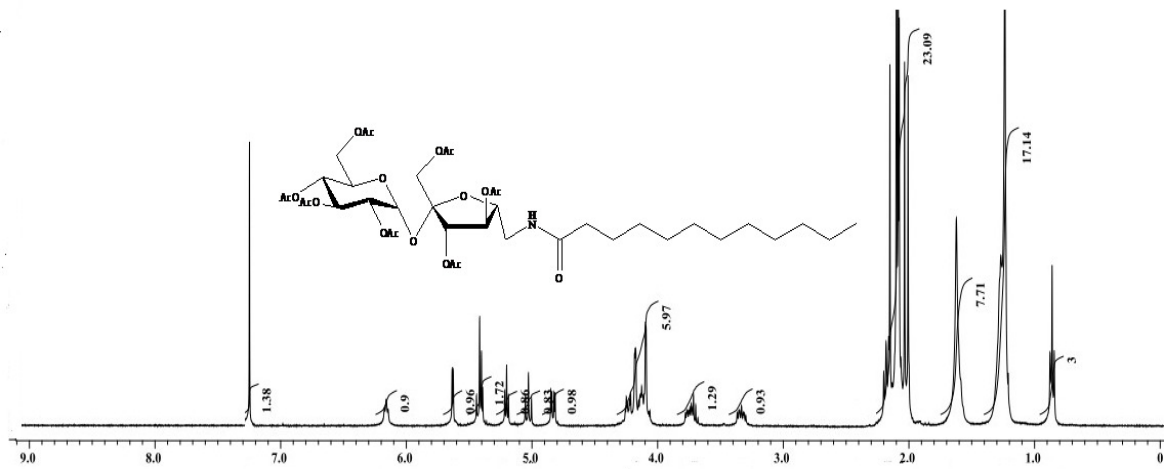

Figure 3. ${ }^{1} \mathrm{H}$ NMR of the acetylated surfactant (7a)

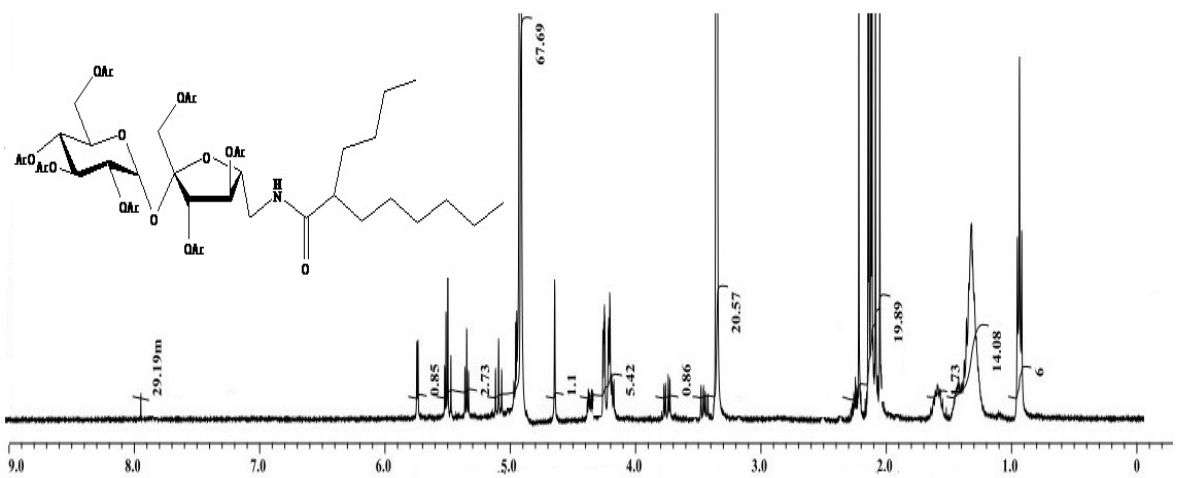

Figure 4. ${ }^{1} \mathrm{H}$ NMR of the acetylated surfactant $(\mathbf{8 a})$

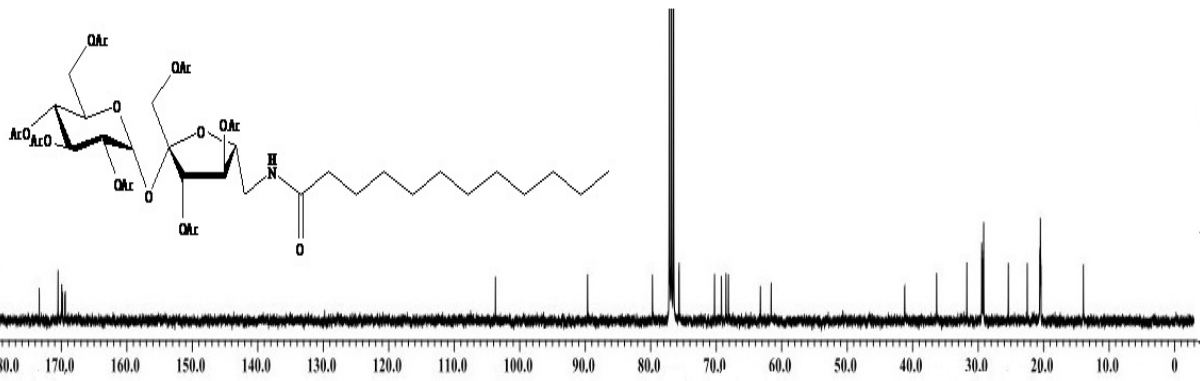

Figure 5. ${ }^{13} \mathrm{C}$ NMR of the acetylated surfactant (7a) 


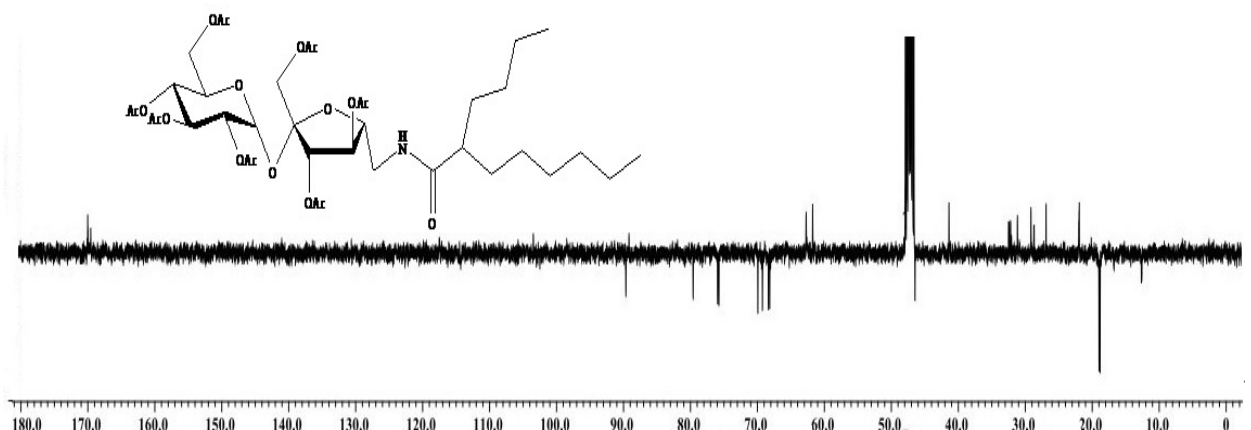

Figure 6. ${ }^{13} \mathrm{C}$ NMR of the acetylated surfactant $(\mathbf{8 a})$

The ${ }^{1} \mathrm{H}$ NMR of deacetylated surfactants are shown in Figures 7 and 8 , the signal of the amide proton in about $\delta 7.80$, the protons of the sugar ring in between $\delta 4.00$ and $\delta 3.30$, while the protons of the alkyl chain appear between $\delta 2.21\left(\alpha-\mathrm{CH}_{2}\right)$ and $\delta 0.91$ (terminal $\mathrm{CH}_{3}$ ). The ${ }^{13} \mathrm{C}$ NMR spectra (Figures $9 \& 10$ ) shows the signal of the amide carbon at about $\delta 175.5$, the signals of sugar carbons in between $\delta 92.16$ (C-1) and $\delta 61.4$ (C-1'), The primary carbon of the fructose found at $\delta 42.29$ (C-6') reflecting the replacement of the hydroxyl group with amide, and the signal of the alkyl chain carbons in between $\delta 35.75$ $\left(\alpha-\mathrm{CH}_{2}\right)$ and $\delta 13.08$ (terminal- $\left.\mathrm{CH}_{3}\right)$.

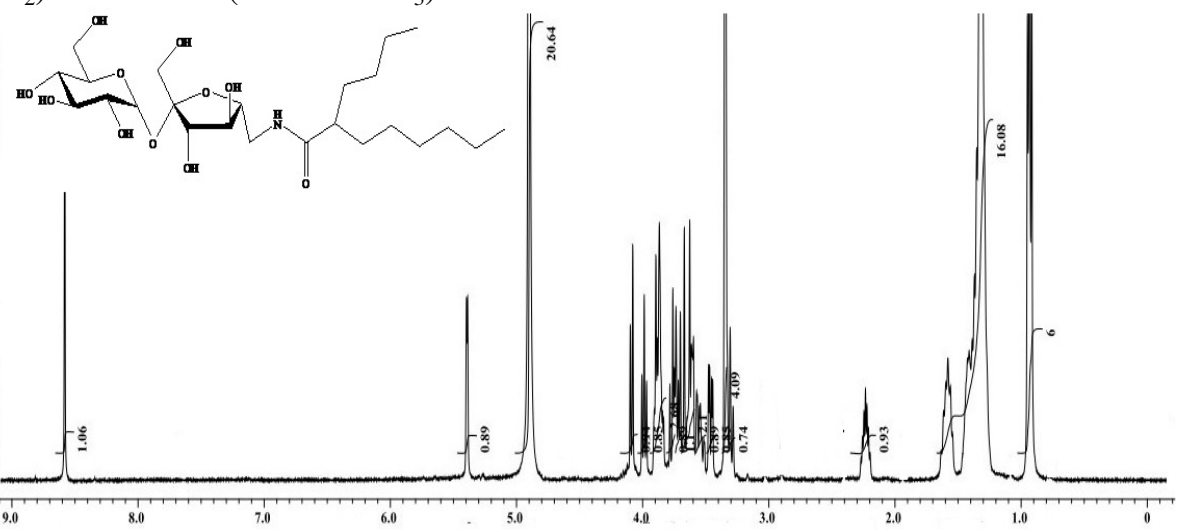

Figure 7. ${ }^{1} \mathrm{H}$ NMR of the deacetylated surfactant (7b)
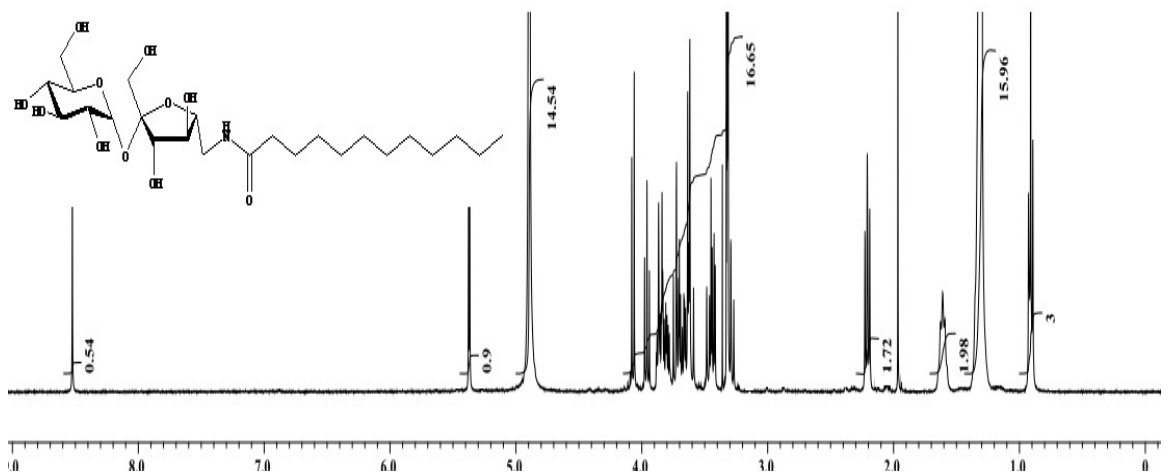

Figure 8. ${ }^{1} \mathrm{H}$ NMR of the deacetylated surfactant $(\mathbf{8 b})$ 

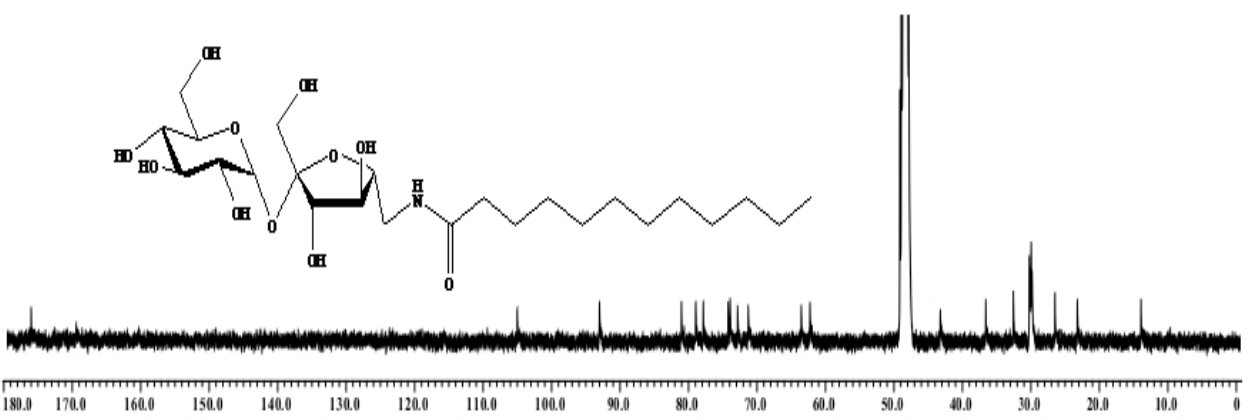

Figure 9. ${ }^{13} \mathrm{C}$ NMR of the deacetylated surfactant $(\mathbf{7 b})$

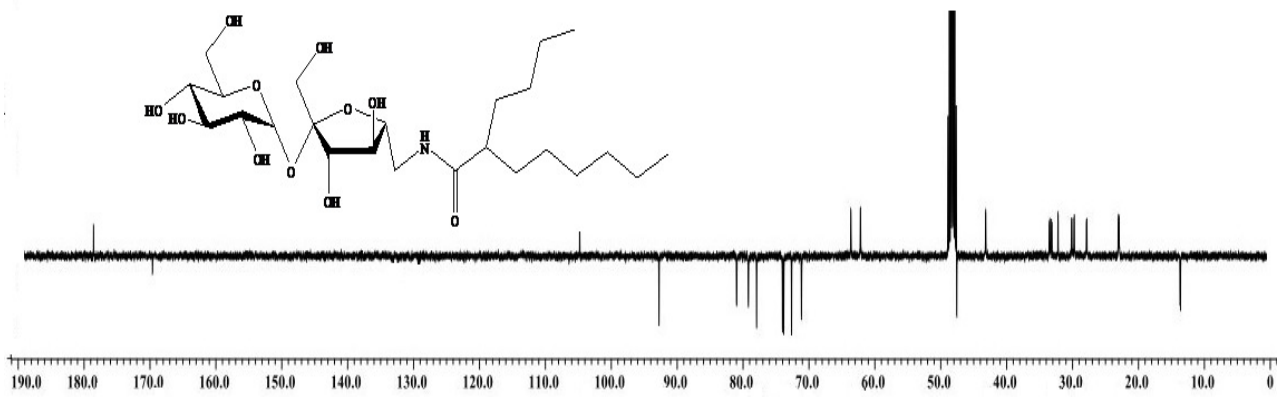

Figure 10. ${ }^{13} \mathrm{C}$ NMR dept. of the deacetylated surfactant $(\mathbf{8 b})$

\section{Physical properties}

Both sucrose amide surfactants $\mathrm{C}_{12}$ straight and corresponding branched are soluble in water at room temperature. The surfactants only exhibit crystalline as a thermotropic phase. The straight surfactant melts at $158{ }^{\circ} \mathrm{C}$ with an enthalpy of $66 \mathrm{~kJ} / \mathrm{mol}$, as shown in Figure 11 . The compound does not crystalline upon cooling. OPM investigations suggest a (partial) decompose of the compound at about $190{ }^{\circ} \mathrm{C}$. In contact with water the micellar phase, $\mathrm{L}_{1}$ is followed by strong birefringent phase refers to hexagonal phase, $\mathrm{H}_{1}$ (Figure 12).

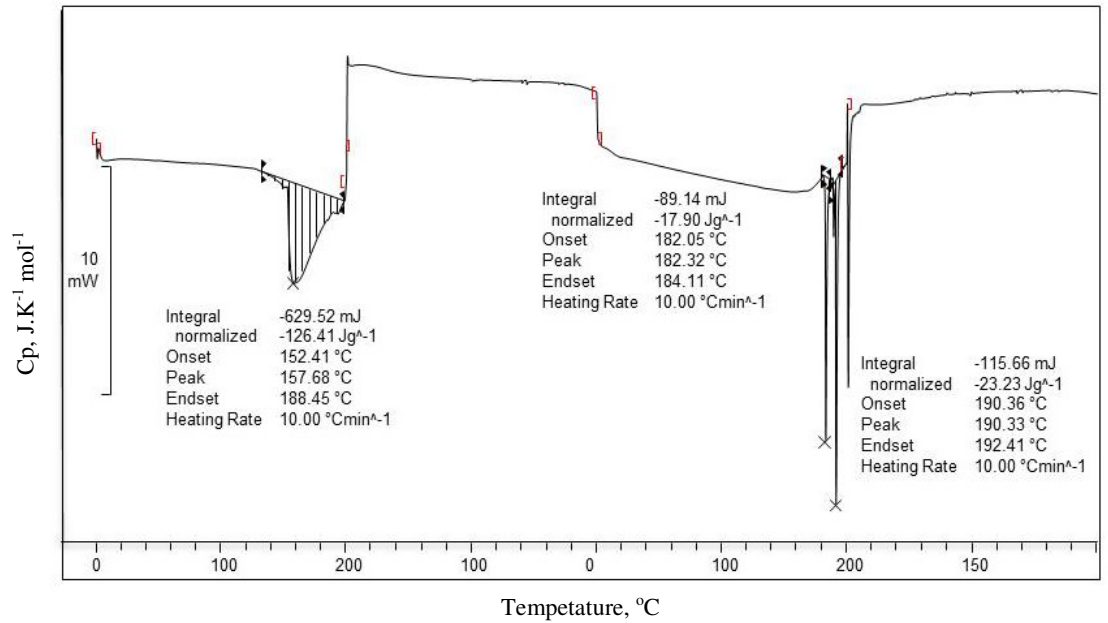

Figure 11. DSC spectrum of the surfactant 6'-dodecanamido-sucrose (7b) 


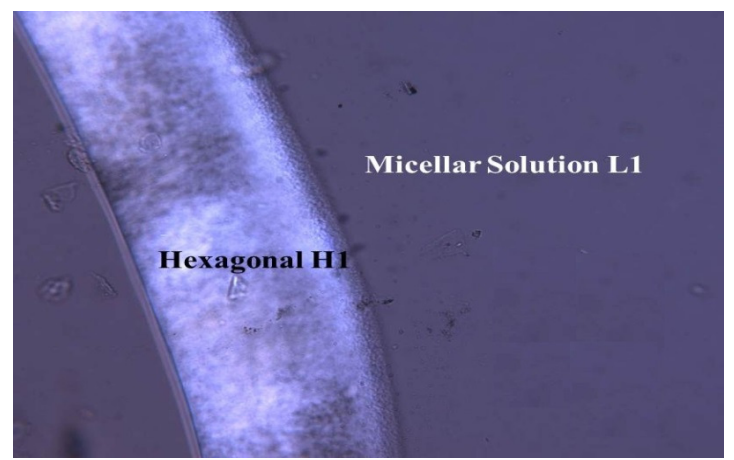

Figure 12. Lyotropic phase ofthe surfactant (7b)

The $\mathrm{CMC}$ of the $\mathrm{C}_{12}$ straight sucrose mono amide surfactants $(\mathbf{7 b})$ was determined at room temperature as $0.7 \mathrm{mmol} / \mathrm{L}$ (Figure 13). This value is in good agreement with other disaccharide surfactants of similar chain length ${ }^{24,25}$. The correlated surface tension of 36 $\mathrm{mN} / \mathrm{m}$ suggested good emulsifying ability. Although less than corresponding glycosides.

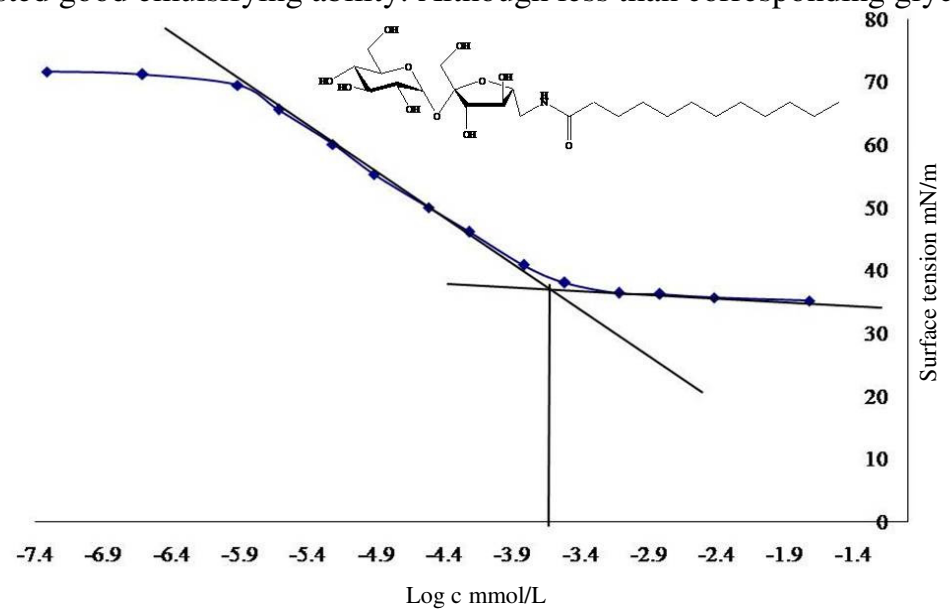

Figure 13. CMS investigation of the surfactant 6'-dodecanamido-sucrose (7b)

\section{References}

1. Blauer R, 2011, Sugar: World Markets and Trade, United States Department of Agriculture Global Sugar Production Steady, While Trade ExpandsReed Blauer

2. Khan R, Pure Appl Chem., 1984, 56(4), 83-84; DOI:10.1351/pac198456040461

3. Linchtenthaler F W and Peters S, Comptes Rendus Chimie, 2004, 7(2), 65-90.

4. Barros M T, Petrova K T and Ramos A M, J Org Chem., 2004, 69(22), 7772-7775; DOI:10.1021/jo048957y

5. Jarosz S, Mach M and Frelek J, J Carbohydrate Chem., 2000, 19(6), 693-715; DOI: $10.1080 / 07328300008544111$

6. Karl H, Cheang C, Lee K and Khan R, Carbohydrate Res., 1982, 101(1), 31-38; DOI:10.1016/S0008-6215(00)80792-2

7. Khan R, Mufti K S and Jenner M R, Carbohydrate Res., 1978, 65(1), 109-113; http://dx.doi.org/10.1016/S0008-6215(00)84217-2 
8. Barros M T, Maycock C D, Sineriz F and Thomassigny C, Tetrahedron, 2000, 56(35), 6511-6516; DOI:10.1016/S0040-4020(00)00593-7

9. Suami T, Ikeda T, Nishiyama S and Adachi R, Bull Chem Soc Jap., 1975, 48(6), 1953-1956; DOI:10.1246/bcsj.48.1953

10. Carvalho I, Andrade P, Camp L, Guedes V, Sesti-Costa P M M P, Silva S, Schenkman R A S, Dedola S, Hill L, Rejzek M, Nepogodiev A and Field S, Bioorg Med Chem., 2010, 18(7), 2412-2427; DOI:10.1016/j.bmc.2010.02.053

11. Li S C, Meng X B, Cai M S and Li J Z, Synthesis Communications, 2006, 637-643; DOI:10.1080/00397910500408787

12. Maunier V, Boullanger P, Lafont D and Chevalier Y, Carbohydr Res., 1997, 299(1-2), 49-57; DOI:10.1016/S0008-6215(96)00336-9

13. Hughes F A and Lew B W, J Am Oil Chem Soc., 1970, 47(5), 162-167

14. Salman, S. M.; Heidelberg, T and Tajuddin H A B, Carbohydrate Res., 2013, 375, 55-62; DOI:10.1016/j.carres.2013.03.028

15. Hough L and Mufti K S, Carbohydrate Res., 1972, 25(2), 497-503; DOI:10.1016/S0008-6215(00)81661-4

16. Neto V, Granet $\mathrm{R}$ and Krausz P, Tetrahedron, 2010, 66(25), 4633-4646; DOI:10.1016/j.tet.2010.03.115

17. Zemplen G, Gereces A and Hadacsy I, Berichte der deutschen chemischen Gesellschaft, 1936, 69B, 1827.

18. Polat T and Linhard R J, J Surfactants Deterg., 2001, 4, 415-421.

19. Hoke B C and Chen J C, J Chem Engg Data, 1991, 36(3), 322-326; DOI:10.1021/je00003a019

20. Spectrometric Identification of Organic Compounds (Eds.); Silverstein R M, Webster F X and Kiemle D, Eds.; John Wiley \& sons Inc: New York, 2005; Vol. $7^{\text {th }}$ Edition.

21. Debenham J S, Rodebaugh R and Fraser-Reid B, J Org Chem., 1997, 62(4), 46014609; DOI:10.1021/jo9706133

22. Laughlin R G, Adv Colloid Interface Sci., 1992, 41, 57-59; DOI:10.1016/00018686(92)80007-K

23. Noüy P L D, J General Physiology, 1919, 1, 521-524; DOI:10.1085/jgp.1.5.521

24. Minden V H M, Brandenburg K, Seydel U, Koch J M H, Garamus V, Willumeit R and Vill V, Chemistry Phys Lip., 2000, 106, 157-176.

25. Milkereit G, Brandenburg K, Gerber S, Koch M H J, Morr M, Andrä J, Seydel U and Vill V, Chemistry and Physics of Lipids, 2005, 135, 15-26; DOI:10.1016/j.chemphyslip.2005.01.007 